\title{
Sistema de informação para gestão da educação personalizada - um estudo de caso
}

\author{
Solange D. P. Sá Barros ${ }^{1}$, Fernando F. Junior ${ }^{1}$, Nattan L. Silva ${ }^{1}$, Renan de B. Silva ${ }^{1}$ \\ ${ }^{1}$ Universidade Presbiteriana Mackenzie - Faculdade de Computação e Informática \\ Rua da Consolação, 930 - Prédio 31 - 01302-907 - São Paulo - SP - Brazil \\ solbarros@mackenzie.br, fernando fortine@live.com, \\ nattanls@yahoo.com.br, renandē̄ritto@gmail.com
}

\begin{abstract}
Amid debates about the ineffectiveness of the current educational system, there emerge alternative and more modern educational systems to deal with this issue. The personalized educational system, or personalized learning system, makes use of more suggestive learning means, considering that each student is a unique human being with exclusive characteristics and skills, and that the school and its parents or guardians have substantial involvement in the development of such individuals. Allied to this context, we observe that the use of technology through information systems could not only become a natural tool in dealing with operational problems, but also a valuable and active part of the educational process. The purpose of this case study was to show how and where the information systems can be useful in the task of educating children through personalized learning, providing theoretical background and detailed documentation of a software that could not only assist trivial tasks, but also support the tracking of the students' development.
\end{abstract}

Resumo. Em meio a debates sobre a ineficácia do sistema educacional vigente, surgem sistemas educacionais alternativos e inovadores para lidar com esta questão. O sistema de ensino personalizado utiliza-se de meios mais sugestivos de aprendizagem, considerando que cada aluno é um ser humano singular, com características e habilidades únicas, e que a escola e os responsáveis têm participação essencial no desenvolvimento de tais indivíduos. Aliado a esse contexto, observa-se que o uso da tecnologia através dos sistemas de informação poderia tornar-se uma ferramenta não apenas natural no trato de problemas operacionais, mas também uma parte valiosa e ativa do processo educacional. O estudo de caso realizado mostra como e onde os sistemas de informação podem ser aproveitados na tarefa de educar crianças que são formadas em instituições que fazem uso da educação personalizada, fornecendo embasamento teórico bem como uma documentação detalhada de um software que não apenas auxilia as tarefas corriqueiras, mas também apoia o acompanhamento do desenvolvimento dos alunos. 
V Congresso Brasileiro de Informática na Educação (CBIE 2016)

Anais do XXVII Simpósio Brasileiro de Informática na Educação (SBIE 2016)

\section{Introdução}

As inovações tecnológicas têm transformado o mundo tradicional que nós conhecemos. $\mathrm{O}$ que antes era feito de maneira manual, muitas vezes comprometendo a qualidade de um processo, tem sido feito de uma maneira mais eficiente através de um computador. Por exemplo, a utilização de mapas em papel por pessoas na condução de um carro está cada vez mais distante em nossa memória. Ao invés disso contamos com poderosos sistemas de informação geográficos que nos direcionam com muito mais conforto e segurança aos nossos destinos. Sem contar as novas áreas de negócio que se tornaram possíveis graças ao uso dos inovadores sistemas de informação. De fato, pode-se dizer que o processo atual e contínuo de solucionar problemas e desafios passa pelos sistemas de informação modernos (Laudon \& Laudon, 2012).

No entanto, enquanto a tecnologia transita neste processo evolutivo e contínuo, a educação se distancia da realidade atualizada, oferecendo à sociedade um modelo arcaico e distante do mundo contemporâneo. Com exceção de países desenvolvidos, como Finlândia e Dinamarca, e em outros nem tanto assim, como o Uruguai (Índice da Educação da ONU, 2009), muitos países ainda não encontraram o nível de educação adequado, especialmente de crianças e jovens. No Brasil, embora existam problemas com infraestrutura nas escolas, incluindo a falta de investimentos substanciais, pode-se notar que muitas vezes o sistema educacional padronizado ao qual as crianças são submetidas mina a sua evolução e até mesmo sua vontade de querer aprender e se desenvolver. Nisso surge a importância da educação personalizada e suas vantagens em comparação ao sistema de educação generalizado.

Uma vez que a Educação Personalizada trata o indivíduo como singular, com necessidades, velocidades de aprendizagem e interesses específicos, identificou-se que instituições que têm como base essa metodologia possui necessidades tão específicas para com os seus alunos, pais, professores e órgãos regulamentadores que se tornou um desafio lidar com todos os processos internos e externos. É daí que surge a ideia de um sistema informatizado que possa auxiliar instituições que fazem uso desta metodologia, e através do estudo de caso é proposta uma ferramenta que auxilia a escola no processo formativo de seus alunos com um sistema que reflete sua estrutura pedagógica, fornecendo informações gráficas de cada estudante.

Seguindo a abordagem sistêmica para solução de problemas de O’Brien (2007), que utiliza "uma orientação de sistemas para definir os problemas e as oportunidades e em resposta desenvolver soluções viáveis e adequadas", ao longo deste trabalho, buscase apresentar os conceitos fundamentais para $o$ entendimento necessário do problema/oportunidade, possíveis soluções de software que respondam às suas necessidades e, finalmente, uma conclusão que dará subsidio para avaliar as alternativas de soluções disponíveis.

\section{Educação Personalizada}

A educação personalizada tem como princípio o homem como indivíduo plenamente singular, com complexidades e características que configuram cada pessoa um ser único, 
V Congresso Brasileiro de Informática na Educação (CBIE 2016)

Anais do XXVII Simpósio Brasileiro de Informática na Educação (SBIE 2016)

e que ao mesmo tempo, tem como natureza a liberdade, a autonomia para decidir qual caminho trilhar em sua vida (Garcia Hoz, 1988).

A personalização da educação intui que o processo central da educação é a construção deste homem, de forma integral e constante, com capacidade e possibilidades de interação com a realidade que o rodeia [...] através de atribuição de responsabilidade, estímulo para autogovernar, estabelecer relações e busca de sentido em sua vida (Buitrago \& Lilia, 2001, tradução nossa).

Sendo assim, o processo pedagógico da educação personalizada entende como primordial o exercício de definir quem é o sujeito a ser exposto a esse estilo educacional. A questão inicial do pensamento filosófico da educação personalizada é "Quem é o Homem?", e a resposta é definida em três pilares: A Singularidade, a Autonomia, e a Abertura (Garcia Hoz, 1995).

Segundo Escobar (1984), a singularidade de cada aluno deve ser preservada e estimulada, pois nela está presente a capacidade criativa de cada um. Dela brota a originalidade, a independência, o espírito empreendedor e a espontaneidade. É da singularidade, também, que nasce a imaginação, curiosidade e inconformismo. Encorajar e nutrir esta qualidade em cada um fará com que os alunos tenham cada vez mais consciência de quem são, e liberdade para a expressão de si mesmo, para que todos sejam beneficiados com a percepção do indivíduo sobre o mundo que vê, sente, julga.

É nesta perspectiva singular que a educação personalizada entende que cada indivíduo possui uma velocidade diferente para obtenção de alguma habilidade, que tem interesses distintos dos outros, que a maneira com que absorve e compreende qualquer tipo de assunto pode ser única ou diferente do grupo que o cerca. É neste ponto que educação personalizada destoa da educação tradicional, onde os alunos, numa tentativa abrupta, precisam andar no ritmo da turma, acompanhar os colegas, ler o livro que alguém determinou, e aos poucos este processo faz que com a singularidade de cada um vá se desfazendo enquanto um molde estabelecido vai tomando o lugar da autonomia do indivíduo.

A autonomia, por sua vez, é a expressão da liberdade humana, a capacidade de decidir por si, o exercício responsável de delinear sua própria jornada. É intrínseca a esta liberdade, a responsabilidade, que deve ser apresentada ao indivíduo para que desenvolva confiança em si mesmo, para que através dela ele possa se manifestar consciente da realidade em que está, e ao educador cabe a tarefa de incentivar e inspirar esta qualidade ao aluno, de autogovernar-se, delegando a ele decisões, instigando a reflexão pelas razões que o inclinaram em suas escolhas (Escobar, 1984).

Inerente a natureza humana está a abertura ao outro. De acordo com Garcia Hoz (1988), o homem possui uma necessidade existencial de se relacionar com pessoas, apresentada pela atitude de se comunicar com o mundo exterior, estabelecendo vínculos que permitem a troca de experiência. A solidariedade pode ser compreendia através deste exercício de vinculação com o outro, onde livremente o indivíduo se disponibiliza a compreender o alguém que é diferente dele. As relações familiares, de amizade e profissional são frutos do imperativo da abertura. 
V Congresso Brasileiro de Informática na Educação (CBIE 2016)

Anais do XXVII Simpósio Brasileiro de Informática na Educação (SBIE 2016)

Diversas instituições incorporaram a educação personalizada em sua maneira de ser escola. Isso significa que não existe um jeito único de se praticar esta pedagogia. No entanto, é irrevogável a necessidade de o aluno ser conhecido individualmente pela organização, que por sua vez é caracterizada pelo corpo docente, ou apenas "tutor".

Em algumas organizações conhecidos como preceptor, o tutor tem diferentes encargos a frente de uma turma, mas uma delas é carregada de uma grande responsabilidade e que faz com que a educação personalizada tenha relevância. $\mathrm{O}$ tutor precisa saber como são e como estão os seus alunos, precisa se inteirar do que se passa com o indivíduo e tem um relacionamento mais próximo com os familiares (Escobar, 1984).

O tutor também atua como orientador, um auxílio ao aluno no que se diz respeito à formação dele, para que harmonicamente o aluno consiga lidar com as situações pessoais e sociais. São na tutoria, conversas frequentes, e no dia a dia do aluno que o tutor identifica as modalidades particulares de cada aluno, o jeito que gosta de aprender, assuntos que o fascina, e através de todos esses apontamentos o tutor se mune de informações que o auxilia o aluno no processo de autoconhecimento (Garcia Hoz, 1988).

É importante esclarecer que a Educação Personalizada não se apresenta como uma alternativa que exclui a utilização da Educação Coletiva. Segundo Garcia Hoz (1995), enquanto a educação personalizada centraliza as necessidades individuais da pessoa e suas características particulares, existem outras necessidades no campo comunitário, os elementos em que todos são caracterizados como semelhantes. Os dois modelos podem ser utilizados em conjunto e, na verdade, acredita-se que esta seja a forma mais adequada para o processo pedagógico.

Ainda, segundo Builtrago e Lilia (2001), a educação personalizada e a educação coletiva são formas incompletas e parciais da educação. As duas modalidades apresentam um papel importante na formação do aluno, que por sua vez possui necessidades particulares e sociais. A educação individual oferece maior atenção ao aluno, oferece maior suporte para que a interioridade de cada pessoa seja fortalecida, e concede um suporte maior para que as dificuldades sejam trabalhadas. Através da educação coletiva o aluno enobrece com o outro totalmente diferente dele, e o trabalho em grupo é o espaço de socialização e estabelecimento de relação entre os alunos.

\section{Proposta de gestão da educação personalizada}

A partir da compreensão da educação personalizada, refletiu-se sobre uma proposta de solução tecnológica para instituições que fazem uso dessa metodologia educacional, e que carecem de ferramentas de software para otimizar seus processos pedagógicos, buscando oferecer um suporte mais eficiente na formação dos alunos.

O estudo de caso foi iniciado através de pesquisas e visitas a instituições que fazem uso da educação personalizada, com a finalidade de compreender a maneira que estas escolas lidam com os processos educacionais e ao mesmo tempo encontrar espaços onde a tecnologia proporcionaria uma experiência formativa de maior relevância. A 
V Congresso Brasileiro de Informática na Educação (CBIE 2016)

Anais do XXVII Simpósio Brasileiro de Informática na Educação (SBIE 2016)

verdade é que todas já utilizavam algum tipo de sistema de informação, tanto nos processos administrativos como, por exemplo, Excel, Access, e sistemas desenvolvidos por eles mesmos, como também nas atividades escolares, Prezi, Power Point, Word, entre outros aplicativos.

Uma vez feita esta análise inicial, surgiu a ideia de criar uma solução tecnológica (aplicação) que se enquadraria no conceito de tratar o indivíduo como único da educação personalizada. Um sistema que colaboraria com uma visão concreta sobre o desenvolvimento de cada aluno dentro de uma instituição. O âmago da proposta é a possibilidade de acompanhar graficamente o desempenho individual de cada estudante, identificando as tendências deles de acordo com os seus trabalhos realizados durante o ano letivo e, a partir dessas informações, o tutor passa a ter uma base sólida para colaborar na formação do indivíduo, assim como o próprio aluno também passa a ter a possibilidade de visualizar sua jornada escolar.

No estudo inicial foi diagnosticado que, além da educação personalizada, as instituições analisadas também eram adeptas de outros modelos paralelamente. Sabe-se que a educação personalizada pode permear outros modelos educativos e que sua metodologia está mais relacionada com a maneira que os alunos são tratados. Houve instituições que utilizam o método tradicional, com exposição de matéria e avaliações bimestrais, e escolas que fazem uso de outras metodologias como, por exemplo, a PBL (Problem Based Learning), onde os alunos são expostos a problemas, estimulados a encontrar soluções e, a partir disso, se desenvolvem em múltiplas áreas do saber.

Independentemente do modelo que as instituições utilizam em paralelo com a educação personalizada, a proposta do sistema é que cada aluno seja responsável por alimentar a ferramenta com informações pessoais do seu cotidiano escolar, como por exemplo, o tema do trabalho que escolheu, o tipo de livro que começou a ler, as áreas do saber que abordou em um determinado projeto, entre outras informações que estejam vinculadas a sua própria decisão no ambiente escolar. A princípio, nossa ferramenta não atende a necessidade de uma instituição que não abre espaço para o aluno decidir coisas do seu dia-a-dia escolar, o que iria contra a lógica da educação personalizada. Quanto mais autônomo o aluno for no seu desenvolvimento, mais a ferramenta se torna eficiente.

A partir da coleta destas informações, o sistema gerará um quadro, que foi nomeado como "O Quadro do Saber", que será subdivido de acordo com uma predefinição da instituição. A Figura 1 apresenta um exemplo de como uma escola pode determinar a disposição das subdivisões dentro do Quadro do Saber. 
V Congresso Brasileiro de Informática na Educação (CBIE 2016)

Anais do XXVII Simpósio Brasileiro de Informática na Educação (SBIE 2016)

\begin{tabular}{|c|c|c|c|c|c|}
\hline GEOMETRIA & TRIGONOMETRIA & ESCRITA & GRAMÁTICA & CARTOGRAFIA & DEMOGRAFIA \\
\hline SOMA & EQUAÇÕES & LITERATURA & ORALIDADE & CONTINENTES & MEIO AMBIENTE \\
\hline SUBTRAÇÃO & GRÁFICOS & PONTUAÇÃO & PRONOMES & PAISES & GEOPOLITICA \\
\hline RESISTÊNCIA & ELETRICIDADE & ESTRUTURA ATÓMICA & ALIMENTOS & $\begin{array}{l}\text { HISTÓRIA DO } \\
\text { BRASIL }\end{array}$ & $\begin{array}{l}\text { HISTÓRIA DO } \\
\text { MUNDO }\end{array}$ \\
\hline MECÂNICA & ELETROMAGNETISMO & QUIMICA ORGÂNICA & COMBUSTIVEIS & ARTE & CULTURA \\
\hline FísICA NUCLEAR & $\begin{array}{l}\text { FiSICA DE } \\
\text { MATERIAIS }\end{array}$ & QUÍMICA NUCLEAR & REAÇÕES & MÚSICA & ARQUITETURA \\
\hline
\end{tabular}

Figura 1 - Modelo do Quadro do Saber Fonte: autoria própria

Vale a pena observar que as áreas dispostas no quadro estão próximas de outras áreas que se relacionam mais diretamente. Uma vez estabelecido o Quadro do Saber, o próximo passo é identificar qual será a fonte de dados para alimentá-lo. Digamos, por exemplo, que nesta escola o aluno faça um trabalho semanalmente sobre o tema que ele desejar e, que numa frequência também semanal, ele entregue ou apresente este trabalho aos colegas de turma. Pode-se assumir este trabalho como a fonte de dados e, a cada trabalho realizado, o aluno é responsável por cadastrá-lo na ferramenta. A partir destas informações, como por exemplo áreas abordadas no trabalho, o quadro interpretaria e apresentaria graficamente quais assuntos ele permeou nos projetos abordados durante o ano letivo. Para isso uma escala de cor é definida, e se faz necessário determinar os critérios para que as subdivisões vão assumindo estas cores de acordo com a frequência que um aluno abordou determinado área do conhecimento.

Geralmente os trabalhos abordam mais de uma área do saber. Um trabalho sobre aviões, por exemplo, pode abordar história, matemática, física, química, entre outras disciplinas. A tabela a seguir indica um "Quadro do Saber" gerado após a realização de trabalhos e o devido cadastramento das áreas estudadas na ferramenta proposta. Em relação ao quadro, quanto mais escura a cor maior é a incidência do conhecimento nos trabalhos do indivíduo, quanto mais clara, menor a incidência (Figura 2). 
V Congresso Brasileiro de Informática na Educação (CBIE 2016)

Anais do XXVII Simpósio Brasileiro de Informática na Educação (SBIE 2016)

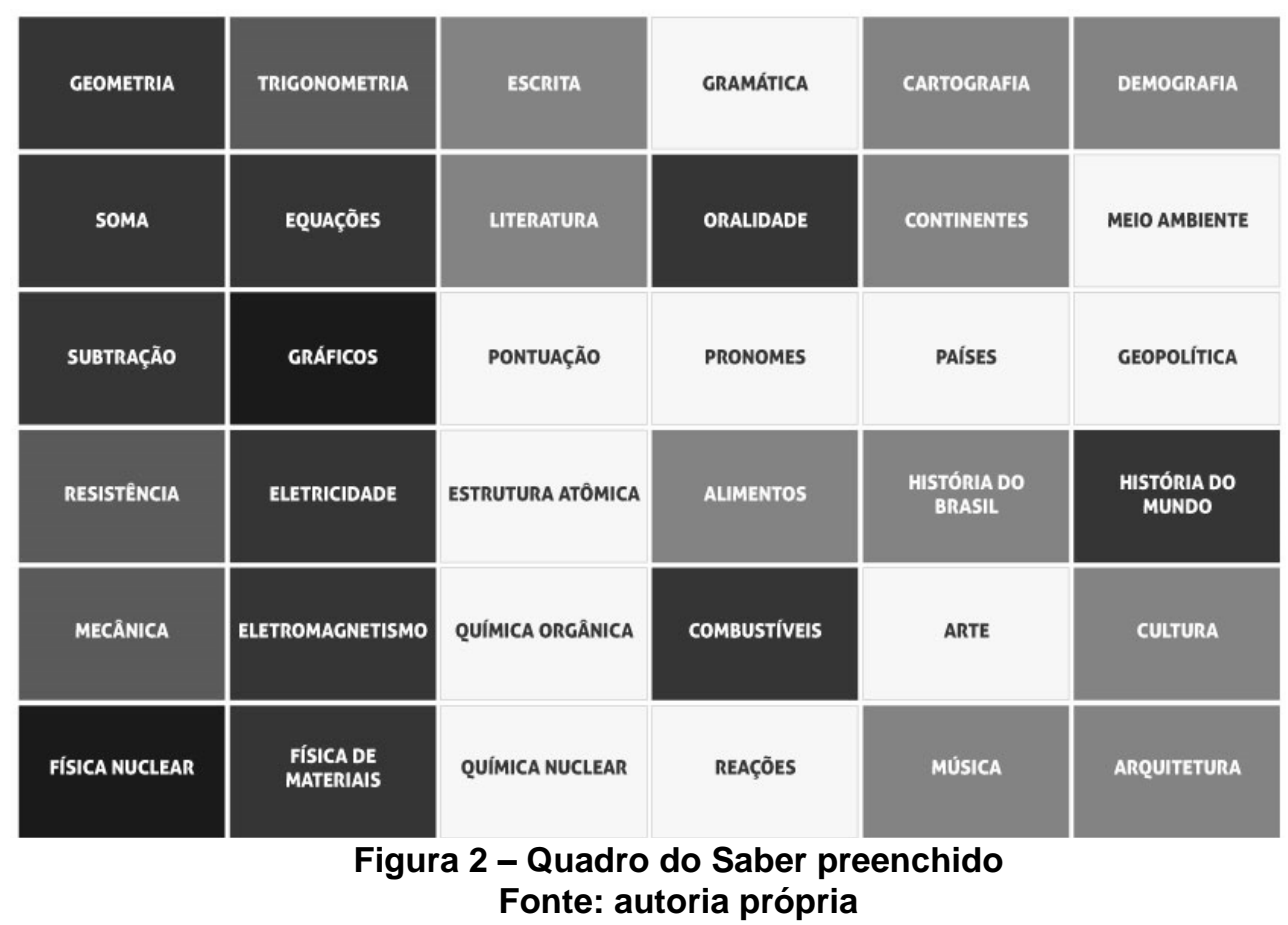

A partir desse quadro, tanto o tutor como o aluno terão acesso a uma exposição visual de como o tempo está sendo utilizado ao longo do ano letivo pelo aluno. Pode-se identificar a carência em áreas que o estudante ainda não abordou, e o tutor poderá orientá-lo a entrar mais em contato com os saberes menos incidentes. Outro ponto importante, é que através deste quadro fica mais claro perceber qual é a tendência do aluno quanto à formação acadêmica e profissional que ele provavelmente irá ter mais afinidade no futuro. Observa-se no quadro de exemplo acima que as áreas que o aluno mais trabalhou até o momento estão relacionadas às ciências exatas. Através disso o professor pode sugerir literaturas sobre temas que permeiam essas áreas, ou oferecer projetos mais complexos que o desafiaria. Neste quadro, por exemplo, o estudante entrou diversas vezes em contato com física nuclear, uma possibilidade de apoio a sua formação seria sugerir documentários sobre o tema, livros, ou até mesmo apresentar a ele grupos de discussão na internet que abordem o assunto.

Por fim, a finalidade do sistema é oferecer informações gráficas sobre as áreas de interesse do aluno para dar suporte à sua formação. O exemplo apresentado acima é somente uma das maneiras e disposições que o Quadro dos Saberes pode assumir, mas a intenção é que para cada instituição deve-se captar a demanda e a metodologia que se aborda para que a customização atenda à necessidade da escola e do aluno.

\section{Estudo de caso}

A escola alvo (EA) deste estudo de caso foi fundada em 2012 e está localizada na cidade de São Roque, em São Paulo, com uma média de 25 alunos por ano, e com uma equipe de aproximadamente 10 professores. A escola nasceu com o intuito de oferecer um espaço de parceria entre os professores e pais, com a finalidade de conceder uma formação singular e de qualidade aos alunos. Suas práticas pedagógicas, fluência com a 
V Congresso Brasileiro de Informática na Educação (CBIE 2016)

Anais do XXVII Simpósio Brasileiro de Informática na Educação (SBIE 2016)

tecnologia e, por trás disso tudo, utilização da educação personalizada, foram os motivos pela escolha desta escola para ilustrar esta pesquisa.

Os alunos da EA encaram diariamente uma jornada diferente do que se espera de uma escola tradicional. Com apoio dos pais e tutores, cada estudante é responsável por elaborar seu plano de ensino, baseado em projetos. Os projetos possibilitam uma abordagem transdisciplinar, aprende-se na prática e, ao mesmo tempo, gerando diálogo entre os saberes. Outro fator importante é que a maioria dos alunos possui um tablet para auxílio nas atividades diárias, assim como os professores também possuem acesso e facilidade para lidar com a tecnologia.

Foram feitas visitas e entrevista com professores da instituição durante $o$ semestre de 2015 com a finalidade de identificar uma forma eficiente da ferramenta de software para colaborar no seu processo pedagógico. Dados foram coletados e, a partir deles, observou-se como os processos se comportam nas tarefas diárias da escola. $\mathrm{O}$ principal processo, levando em conta que este é o mais importante para o sistema pois é a partir dele que o mesmo será alimentado, é o de cadastro de projetos. Como dito anteriormente os alunos aprendem a partir de projetos e, para cada projeto desenvolvido, $\mathrm{o}$ aluno preenche uma folha com todas as informações do projeto em questão. Esta folha o acompanha até o fim do projeto, e após seu término é arquivado.

A proposta inicial é que o sistema incorpore a função de cadastro de projeto, que atualmente é feita em papel e que, junto com os professores da EA e os envolvidos neste projeto, seja arquitetado o quadro dos saberes de acordo com as necessidades e preferências da instituição. Para isso foi-se realizada a especificação do sistema (levantamento de requisitos, documento de requisitos, Modelo Entidade Relacionamento e protótipo), e uma vez aprovado por todos a ferramenta foi desenvolvida. A ferramenta de administração dos conhecimentos para educação personalizada, foi criada em forma de protótipo e foi batizada de "SISTEMA POLO". As principais telas que compõem esse protótipo, são apresentadas nas figuras a seguir.

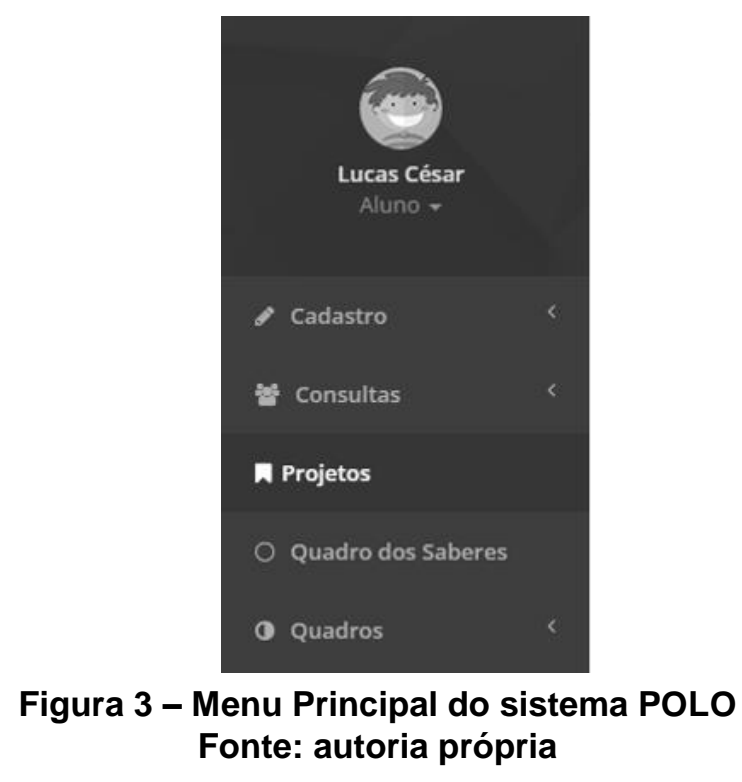


V Congresso Brasileiro de Informática na Educação (CBIE 2016)

Anais do XXVII Simpósio Brasileiro de Informática na Educação (SBIE 2016)

O menu principal do sistema (Figura 3) apresenta as opções de cadastro de projetos, consultas e atualização dos saberes para a confecção do Quadro dos Saberes, que é sempre feita pelo próprio aluno. $\mathrm{O}$ cadastro do projeto envolve, entre outras informações, a definição do orientador, dos coautores e das áreas do conhecimento abordado no projeto (Figura 4).

O aluno poderá, então, consultar o andamento dos projetos que está desenvolvendo (Figura 5), bem como alimentar o Quadro de Saberes (Figura 6).
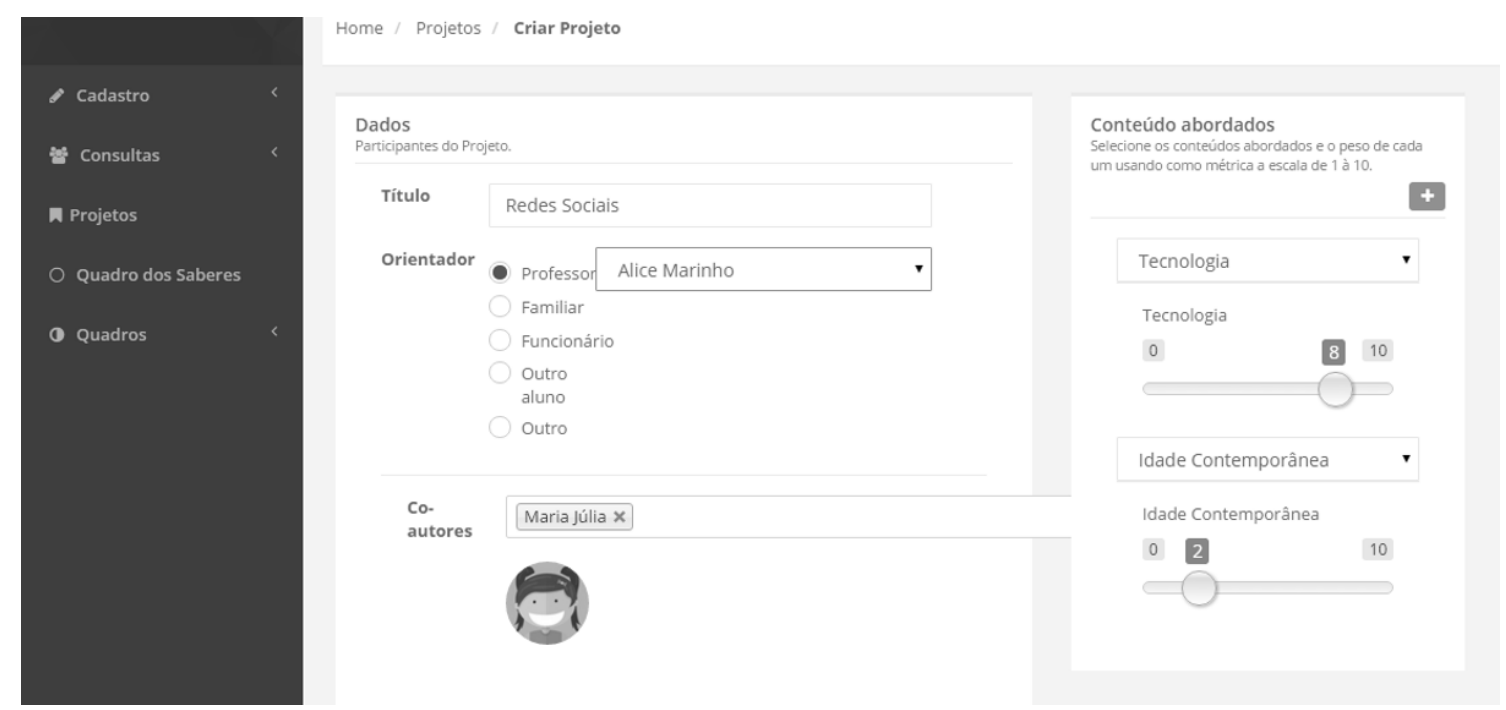

Figura 4 - Cadastro de projeto no sistema POLO

Fonte: autoria própria
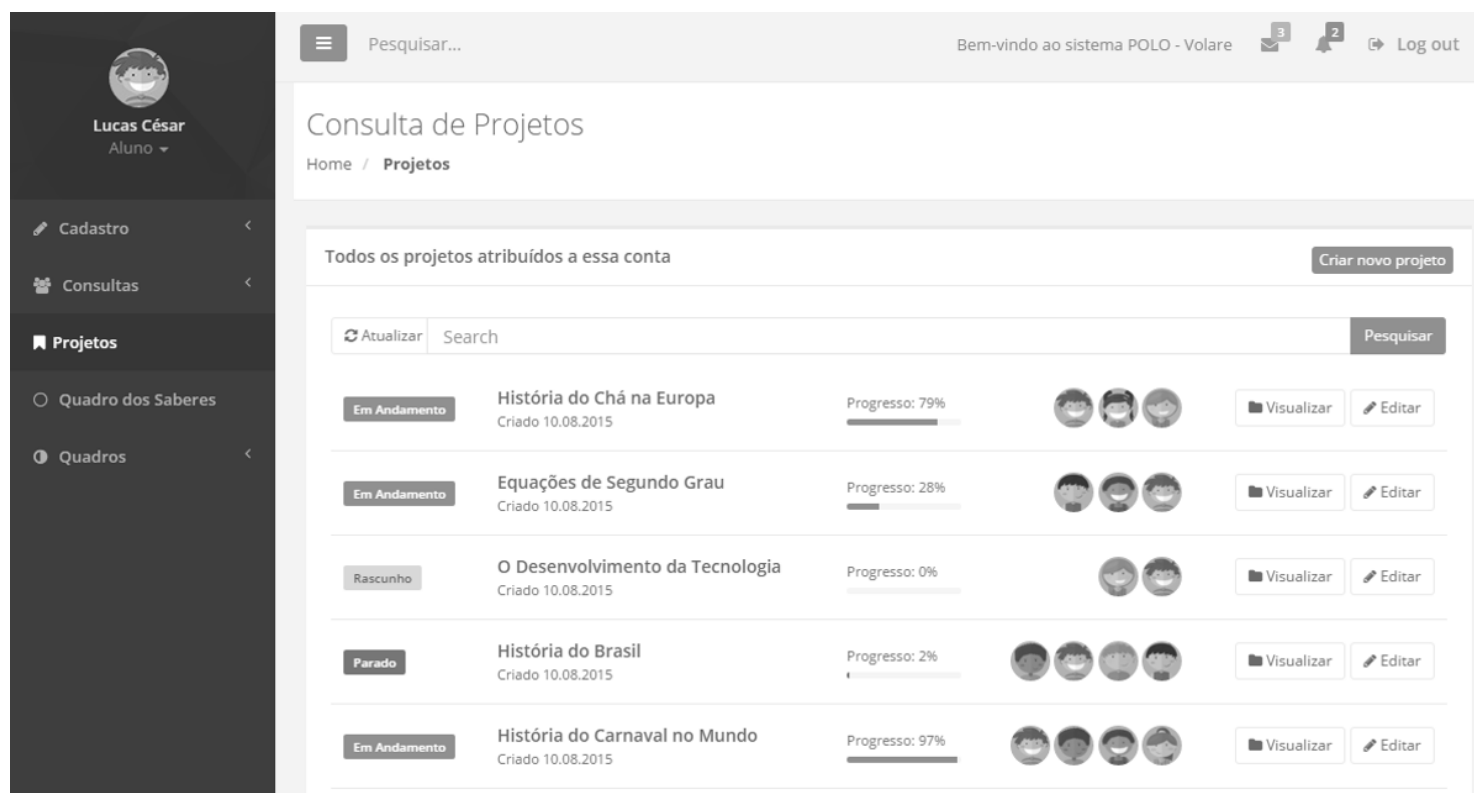

Figura 5 - Consulta aos projetos no sistema POLO

Fonte: autoria própria 
V Congresso Brasileiro de Informática na Educação (CBIE 2016)

Anais do XXVII Simpósio Brasileiro de Informática na Educação (SBIE 2016)
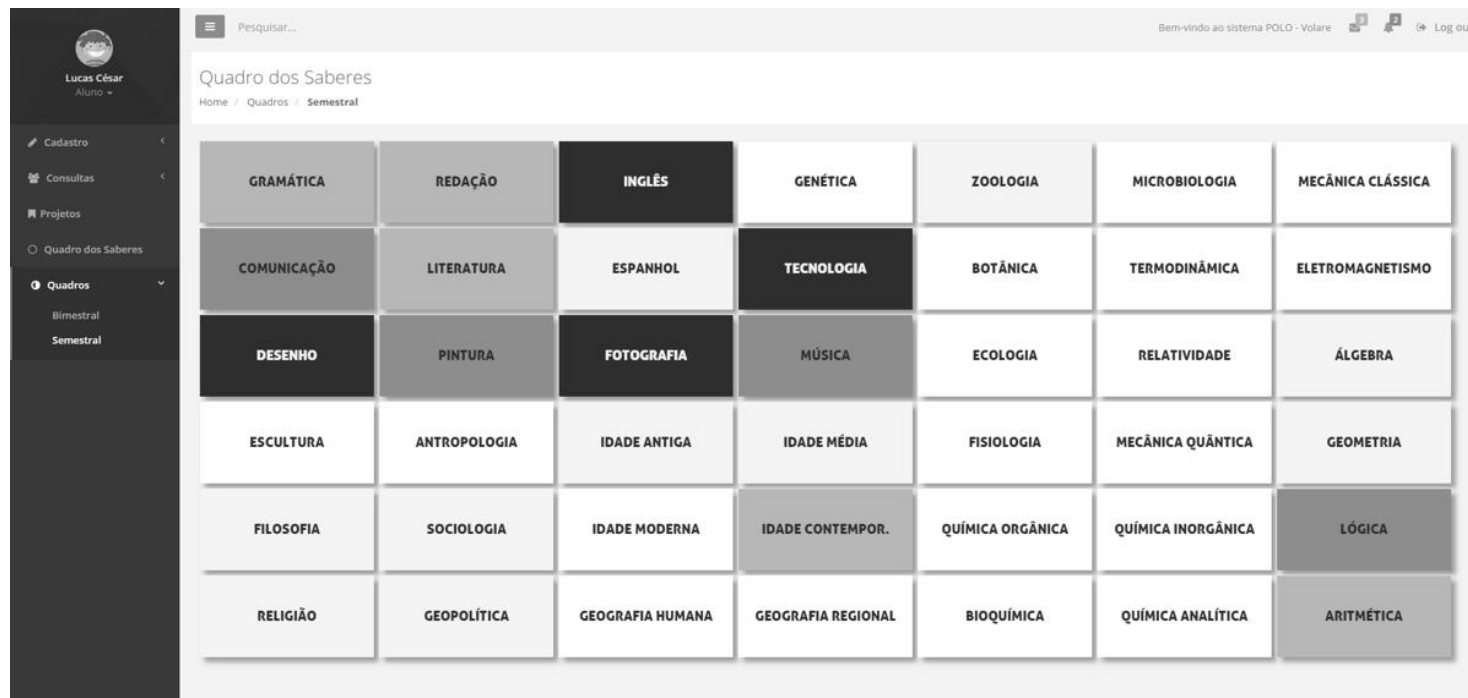

Figura 6 - Alimentação do Quadro dos Saberes no sistema POLO

Fonte: autoria própria

\section{Conclusão}

Através de todas as pesquisas e visitas realizadas durante a construção deste trabalho, e também toda análise e reflexão das informações coletados neste período, foi evidenciado a relevância da tecnologia da informação, mais precisamente os sistemas de informação, para o cotidiano da sociedade, assim como para as áreas educacionais e de aprimoramento humano.

A singularidade da educação personalizada em relação às demais metodologias pedagógicas mostrou-se com necessidades peculiares que os sistemas educacionais atuais não conseguem suprir devido as diferenças estruturais pedagógicas. Para que seja preservada a "personalização" abordada nesta metodologia educacional em um sistema de informação, identificou-se como uma solução adequada o desenvolvimento de uma ferramenta construída de acordo com os traços e requisitos que uma instituição adepta à educação personalizada possui.

A proposta deste sistema mostra-se inovadora, e no mundo atual, os protagonistas são os que se permitem ser inovadores, não só através de sistemas, mas também através de metodologias e processos educacionais. Isso é percebido na própria educação personalizada, uma vez que esta oferece um novo caminho para educar. Nas pesquisas realizadas, identificou-se que escolas ao redor do mundo têm adotado este processo, e isso reflete uma tendência de modificação nas estruturas educacionais nos próximos anos.

Consciente destas transformações, os próximos passos desse projeto é o desenvolvimento desta ferramenta, que apresenta uma ideia catalisadora que auxiliaria não só na formação dos alunos, mas também da estruturação e solidificação de processos pedagógicos inovadores, possibilitando mudanças e novos horizontes para a educação no nosso país e no mundo. Através da construção deste sistema e a análise de 
V Congresso Brasileiro de Informática na Educação (CBIE 2016)

Anais do XXVII Simpósio Brasileiro de Informática na Educação (SBIE 2016)

seus resultados, outras instituições que fazem uso da educação personalizada também podem se beneficiar com o acesso a ela.

\section{Referências}

Buitrago, O., y Lilia, B. (2001). Educación personalizada, una modalidade educativa. Revista de Ciencias Humana, 26.

Escobar, Álvaro Velez. Prática da educação personalizada. São Paulo: Loyola, 1984

García Hoz, Victor et al. Del fin a los objetivos de la educación personalizada. Madrid: Rialp, 1995.

García Hoz, Victor. Educación personalizada. Madrid: Rialp, 1988.

Jerez, O. B.; Amaya, B. L. Educación personalizada, una modalidad educativa. Revista de Ciências Humanas, Pereira, n. 26, p. 1, 2001. Disponível em: $<$ http://www.utp.edu.co/ chumanas/revistas/revistas/rev26/buitrago.htm> Acesso em: 13 abr. 2016.

Laudon, Kenneth C.; Laudon, Jane P. Sistemas de Informação Gerenciais. 9. ed. São Paulo: Pearson Education do Brasil, 2012.

O’brien, James A.; Marakas, George M. Administração de Sistemas de Informação: Uma Introdução. 13. ed. São Paulo: McGraw-Hill, 2007.

ONU. Organização Das Nações Unidas. Índice do Desenvolvimento Humano: Índice da Educação. 2009.

Sommerville, Ian. Engenharia de Software. 6. ed. São Paulo: Pearson. 2005.

Turban, Efraim; Rainer, R. Kelly, Jr.; Potter, Richard E. Introdução a Sistemas de Informação: Uma Abordagem Gerencial. Rio de Janeiro: Elsevier, 2007.Boulic, R. and Renault, O. (1991) "3D Hierarchies for Animation", In: New Trends in Animation and Visualization, Edited by Nadia Magnenat-Thalmann and Daniel Thalmann, John Wiley \& Sons ltd., England. 